\title{
The Bracketing of Presence: Dematerialization and Disembodiment in Times of Pandemic and of Social Distancing Biopolitics
}

\author{
Giovanni Stanghellini ${ }^{a, b}$ Louis Sass ${ }^{c}$ \\ aDepartment of Psychological, Health and Territorial Sciences, "G. d'Annunzio" University, Chieti, Italy; ' "D. Portales" \\ University, Santiago, Chile; 'Rutgers University, Piscataway, NJ, USA
}

\section{Keywords}

Culture $\cdot$ Embodiment · Intersubjectivity · Phenomenology · Psychopathology

\begin{abstract}
The purpose of this paper is to help us understand how and why the COVID pandemic, and its associated biopolitics of social distancing, may have affected our relationships with our own bodies and other persons, thus helping to accelerate what might be termed a bracketing of presence that was already well underway in our modern and contemporary social practices. We focus on 3 historical vectors, all rooted in specific technologies, that have profound implications at the levels of our social imaginary and prereflective ways of being: architecture, social media, and medicine. Architecture has progressively eliminated "porosity" between spaces by establishing clear borders between public and private spaces (also within the private ones), thereby contributing to our drive for social distancing. Social media have provided apparatuses that replace intercorporeal encounters with disembodied, virtual interactions mediated by images. Visual experiences that are more embodied, participatory, and "immersed" are replaced by passive forms of "seeing": the other becomes an image for me, and I for the other. The object of medicine has also recently dematerialized with the advent of the new "optical" and "digital" machines of modern med-
\end{abstract}

karger@karger.com

(c) 2021 S. Karger AG, Basel

www.karger.com/psp

Karger" icine, which can operate remotely thanks to an increasingly powerful interface reliant on computational power and the resources of artificial intelligence, thereby dispensing with body-to-body interactions. We offer these reflections as routes to a better understanding of changes that have occurred and are occurring on the planes of both culture and individual psychological existence.

(c) 2021 S. Karger AG, Basel

\section{Introduction}

Our social practices are often shaped by a set of sedimented meanings and narratives of which we are largely unaware. These constitute the implicit background largely prethematic and prereflective - of the social or cultural imaginary that shapes our views, our actions, and our embodied orientation in the world. The purpose of this paper is to bring out some aspects of this culturally grounded psychological orientation that may help us understand how and why the COVID pandemic, and its associated biopolitics of social distancing, may have affected - and may increasingly affect - our lifeworld as well as our worldview, particularly regarding our relationships to our own bodies and other persons. This article is in no way intended to be read as a critique of current biopolitical policies adopted to curtail the pandemic. Such policies 
must obviously be assessed in light of epidemiological and other sociomedical considerations that are not considered in this essay.

Here we will focus on 3 main features of our social imaginary, each corresponding to a specific technological domain relevant to our social practices; these are architecture, social media, and medicine. The practice of architecture is devoted, in large measure, to the delimiting of space; and it has contributed, at least since the times of massive urbanization, largely to the separating of human bodies from one other. The domain of social media is also concerned with space, in this case to connect individuals who are distant from one another, though often at the cost of disembodying individual persons and their relationships. Medicine is devoted to the curing of actual human bodies of flesh and blood, yet in recent years has come to rely on imaging and digital practices that tend to dematerialize both its object (the body) and its practice (the doctor-patient relationship).

Considered in this light, the social distancing required by the COVID-19 pandemic can be understood to have helped to accelerate what might be termed a bracketing of presence that was already well underway in our modern and contemporary social practices. In this context, "presence" [1] refers to a relationship of a human person to the world and its objects: something that is "present" is tangible for human hands and able to be in immediate contact with human bodies. The bracketing of presence entails processes whereby human existence is both disembodied and dematerialized. One side effect of the pandemic is that it may contribute to revealing the nature and impact, on embodiment and intersubjectivity, of these technology-driven developments that are at work in contemporary Western society.

Before we consider these 3 cultural vectors, each of which contributes to an increasing sense of social distancing, disembodiment, and dematerialization, it is useful to look first at a relevant psychopathological condition that has been analyzed in the clinical-phenomenological literature, long before the COVID era, namely, the extreme fear of contamination, which can transform the lifeworld in major ways.

\section{Contamination Obsession: A Paradigm for Social Distancing Biopolitics}

During the 1930s and 1940s, two German psychopathologists with a phenomenological orientation, Erwin Straus [2] and Victor von Gebsattel [3], independently explored the world of persons who fear to be contaminated and seek to avoid contagion at all costs - what Straus termed "contamination obsession." Their parallel accounts offer a phenomenological paradigm for contemporary social distancing biopolitics. In contamination obsession, most of the world is perceived in accord with the physiognomy of decay - what Straus calls aneidos, that is, the loss of form of a given thing in the world. For the obsessive person the world is not inhabited by living things or useful objects that appear as opportunities and obstacles in the process of life, but by mere matter destined to decompose and die: "the world in which the obsessives live has such a structure that their behavior is dominated by horror and dread, not because of fear of death which may hit them in the near future, but because of the presence of death in sensory immediateness, warded off in disgust" [2].

Indeed, the term "obsession" comes from the Latin "obsidere," which means to besiege. Obsession originally has a spatial significance: an obsessive person feels literally besieged; her livable space shrinks as things in the environment seem to be getting too close and shrinks further with her defensive efforts to avoid contamination.

In "The case of Lola Voss," another German-speaking psychiatrist, Ludwig Binswanger [4], describes an instance of contamination obsession turning into a fullblown psychosis. The lived space of the patient, Lola, is altered, as it comes to be organized around "infectious focuses" that she feels are pressing too close to her and to other things. Lola interprets everything on the basis of spatial vicinity: objects pass their terrifying qualities on to whatever is next to them. The result is that she cannot spontaneously inhabit space but must reflexively "read" it - endlessly interpreting her environment according to magic rules and looking for "signs" to help sort out what can and cannot be touched without fear of contagion. Sometimes she tries to artificially enlarge space by closing her eyes, to magically keep the contagion at bay.

The Italian clinical phenomenologist Lorenzo Calvi [5] offers a similar account: "between the surface of the body and that of objects, in the place where they consume each other, there is a category of invisible and omnipresent things, things that jump from one surface to the other and are absolutely ungraspable. Nobody has seen germs but, if they do truly exist, this means that there are things that are mobile, unreliable, and unsafe, yet pretend to be inoffensive. It is impossible to demonstrate that all this is not true for all things" [our translation and italics, p. 92]. 
As the phenomenological accounts show, the lifeworld of persons with contamination obsession can be portrayed in a dual fashion:

1. Lived space is characterized by extreme and omnipresent "contiguity": anything can seem contiguous to the person and to anything else as well. Things just feel too near. Accordingly, microscopic aspects of reality what should be experienced only up close - emerge into a kind of visibility. Things appear as they might under a microscope: polluted with microbes that seem to jump constantly about from one spot to another and to proliferate endlessly. Germs can rapidly invade such a space because there is, in fact, little or no distance to cover. All that had been stable or steady now devolves into a flux of endless alteration, instantaneous contamination, and unstoppable decay. Obviously, this is not a matter of real visual perception of actual microbes. It is a feeling, almost a mood: grounded in a sense of the something fleeting, occult, uncontrollable, and menacing, of quasi life-forms squirming on the surface of things - of proliferating life-forms that paradoxically are the messengers and progenitors of death and decay. With his microscopic view, the person with contamination obsession notices the minuscule and pullulating movements on any surface, the imperceptible vibrations of life and death that go on even though unseen - always passing from one object to another, perhaps onto and into one's own body.

2. All this leads to endless and despairing efforts to redefine confines and distances. Compulsive rituals are necessary, serving as desperate, defensive attempts to organize one's space. All that may appear, to an external observer, as irrational or meaningless in such a person's behavior, is actually their attempt of regaining control over their environment, to overcome this threat. Order, established through rituals that have become compulsive, should impede contamination: it is crucial to organize a space in which things will not be able to circulate freely, a well-organized space that might slow the dangerous intercourse and flow. Borders, limited areas, and enclosures: these are the spatial elements impeding contamination.

\section{Architecture and the Fall of Porosity}

The same phenomena that Straus, v. Gebsattel, Binswanger, and Calvi described in a psychopathological framework were observed by Walter Benjamin [6] in an urbanistic context in his essays on Naples written in 1925
- though seen here in a very different light. Benjamin's essay is centered on the phenomenon he calls "porosity" (German Porosität).

"In Naples the architecture is as porous as the rock" - he writes. Roughly, we can say that we construct houses and buildings to separate one space from another, as for instance my house must above all be distinct from the house in front of me and from the street that stands in between the two. The basic need to which building a house corresponds is that of isolation. People may of course flow through, from one house to another. Still, building is delimiting a space. By means of physical boundaries, we establish a principle of difference in space, an order that can be both functional and social. The first man who built a hut highlighted a special human power toward nature: cutting a part from the infinite continuity of space. As an example, we may mention the closely related terms that in several languages are used to designate a dwelling space: the English word "apartment" ("flat"), Italian "appartamento," Spanish "apartamiento," French "apa," and German "apartment" ("Wohnung") - they all derive from the Latin verb appartare which means to separate. Architecture is the technique that defines "a fragment of space unified in itself and separated from the rest of the world," wrote Georg Simmel [7] in his book Bridge and Tower.

Benjamin notes that in Naples one feels less isolated because of "porosity," for better or worse. Yet in 1920, in Naples, everything is "permeated" (pressed through) with everything else. There, it seemed to Benjamin, houses are flooded by the street, and vice versa; the coffeehouses and bars have no clear boundaries between inside and outside and function instead as "true laboratories for this grand process of permeation" - all this in a porous world in which families and neighbors swirl together in relationships, in which holidays permeate each workday. The same can be said about day and night, noise and peace, outer light and inner darkness. "Buildings are used as a popular stage," Benjamin writes. "They are all divided into countless theaters with different plays all running at the same time. Balconies, courtyards, windows, entrance ways, staircases, roofs all become stages and box seats... the living room shifts out to the street, with chairs, hearth, and altar... and the street moves into the living room... each private attitude or act is permeated by streams of communal life."

Porosity is a quality that can make a city either more livable or less livable - and the people of Naples, to Benjamin at least, seemed to experience it in a positive way. "[P]overty," he wrote, "has brought about a stretching of frontiers that reflects the most radiant freedom of thought." 
Porosity is thus the antithesis of separatedness: in Benjamin's imagination, and perhaps in that of the Napoletanos, it is an escape from the coldness and isolation the latter can represent. In contrast with the Neapolitan porosity Benjamin describes, we can see most of modern architecture as the attempt to abolish porosity from our life by establishing clear borders between public and private spaces (also within the private ones), thereby to limit and subjugate our drive for sociality, and perhaps to enhance, even to exalt, our drive for social distancing.

In addition to this, it is interesting to point out that in contrast to the separative architecture, in social media there is rather an increased "porosity," that is, a dissolution of the boundaries between public and private spheres. This could be interpreted in such a way that we accept a growing dissolution of boundaries or homogenization precisely in virtual environments, while embodied encounters in reality decrease.

\section{Social Media and the Power of Ocularcentrism}

There is a historical and perhaps anthropological trajectory from porosity to separation, from acceptance and even indulgence of the former to a demand, increasingly insistent, on the latter. Closely corresponding to this is a trajectory from tactile to visual perception.

In his famous essay, The Work of Art in the Age of Mechanical Reproduction [8], Walter Benjamin discusses how human sense perception is influenced by historical circumstances. Everyone knows that our experiencing of particular kinds of objects or works of art as being beautiful or ugly is historically determined, in large measure. Benjamin goes beyond this to consider how the sense modalities, the very "medium" of our experience of the world, can change over the course of time. The ways in which human sense perception is organized, the mode or medium in which it is accomplished, is conditioned by historical circumstances: "during long periods of history, the mode of human sense perception changes with humanity's entire mode of existence" [p. 216]. One key example is this gradual shift from more to less embodied forms of perception that accompanies the onset of modernity.

Sight is the dominant medium implicated in contemporary society. Our ocularcentrism [9] is not only the philosophical subtext of the modern and postmodern value structure; it also permeates contemporary pop culture and social practices, as argued by (among others) Guy Debord [10] in The Society of the Spectacle or Pier Paolo Pasolini [11] in his Disappearance of the Fireflies. Debord uses the term "spectacle" to refer to vision's dominant role in our lives. The "society of the spectacle" has an alienating power; within its domain social relations are mediated by the imagistic representations imposed by media and its implicit or explicit advertisements.

Debord describes how the predominance of sight affects our way of experiencing the world and ourselves: "for one to whom the real world becomes real images, mere images are transformed into real beings" (thesis 18). In the society of the spectacle, sight - the most abstract of senses, and (it has been said) the most easily deceived comes to dominate our experiential universe; it replaces touch as the ultimate index (becomes the touchstone, as we might say) of what seems real.

In the resulting ocularcentric society, not only does the individual become a passive receptor of images coming from the media; relationships between people also come increasingly to be mediated, even produced, by images. The other becomes an image for me - and I an image for the other. In such a society, the more embodied, participatory, and "immersed" kinds of visual experience are replaced by passive forms of "seeing": a disembodied witnessing of mere images and representations.

\section{Medicine and the Rise of Imaging and Digitization}

Medicine offers both a body of knowledge and a technology directed toward healing the human body. Historically, it has been perhaps the most materialistic among the many forms of knowledge and technical expertise that Europe has developed and practiced, always focusing on the most concrete and terrestrial aspects of the human being. Through biomedical technology we have gained unprecedented access to our bodies and their functions, expanding our knowledge of their mechanisms and the efficacy of our interventions on them.

The object of medicine has recently dematerialized, however. Gilles Deleuze [12] follows Michel Foucault's [13] lead in arguing that the ambition of medicine since the Renaissance has been to build a science uniquely based on the sense of sight - indeed to become a kind of "optical machine" (see the discussion of Foucault's Naissance de la clinique in Deleuze's book, Foucault). Imaging techniques, many of recent invention, now allow increasingly refined approaches to diagnosis and intervention that were unthinkable until just a few years ago. The new and updated "optical machine" of modern medicine can operate remotely, thanks to an increasingly powerful interface reliant on computational power and the resources 
of artificial intelligence. Digital phenotyping provides an emblematic example. This approach is based on sensors that detect the individual's activity, location, voice, and speech, based on, perhaps the most important, humancomputer interactions. It contributes to more accurate and earlier diagnoses, while its version of telecare involves the distant monitoring of patients, allowing them to be treated in a timely and continuous manner [14]. For instance - it is argued - our assessment of depression depends largely on self-reports of sleep, appetite, and emotional state, although we recognize that people with depression can be very biased in their assessments. The smartphone can offer a source of measurement that is objective (not biased by subjective self-reports), ecological (reflecting how people function in their world, not in our clinic), and continuous [15].

These techniques obviously offer various advantages, but they also raise concerns, which can be encapsulated in the following questions: is technology, like digital phenotyping, merely a "tool" to achieve improvements in medical practice? Should we consider it as no more than an extrinsic device that is largely irrelevant to how human beings experience and represent their bodies, interpersonal relationships, and forms of human existence in general? Or, does technology of these kinds necessarily alter something of what it is to be a human person, especially our embodiment and our relationships - and not only in the clinical setting [16]?

The digital clinician may even be led by his technological apparatus to neglect or discount the ways in which actual things in the actual world materially act on other such things, and be tempted instead to experience the world as a matter of correlated fluctuations of certain overall processes, understood in rather abstract terms. In this sort of epistemic field, diagnosis becomes mainly a matter of monitoring these fluctuations. To the digital clinician, these variations are not hidden causes in the interior space of an invisible but material body. The digital clinician is studying the covariance of two sets of variables chosen for observation in a digitalized body and may no longer be inclined to think in terms of causes and effects. And along with this dematerialization may go a certain de-psychologization: for the clinician may become less interested in seeking an understanding the personal reasons for a given behavior, or how it feels like to that patient to behave in a given way.

The doctor or other expert or technician in the health sciences, and to some extent the patient as well, will consequently come to dwell in a plane that is tilted, both epistemologically and ontologically, in a certain way. This is not so much because reality is made in such a manner, but because the instrument on which he or she relies have a certain slant [17]. All of us - doctors, patients, and other medical personnel - come to be spellbound to the digits and curves that can be seen on the screen. We focus on dematerialized bodies, images, algorithms, processes, covariance, etc., rather than on physical bodies, words, personal stories, discrete events, causes, and reasons, etc.

\section{COVID-19 Pandemic as an Accelerator of These Vectors}

We have described three historical vectors, all rooted in specific technologies, that have profound implications at the levels of our social imaginary and prereflective ways of being. Over the course of the last century or more, these vectors have led to an increasing bracketing of immediate presence and to a growing sense of social distancing, disembodiment, and dematerialization.

Architecture has contributed to social distancing by progressively eliminating porosity between spaces, delineating fragments of space as unified in themselves and separated from the rest of the world - as is so clear in most of our urban environments. Social media have provided apparatuses to transform social relations, replacing intercorporeal encounters with disembodied, virtual interactions mediated by images. Digital medicine, with its focus on algorithms, processes, and statistical abstractions, is downplaying the fact that we exist as physical bodies and psychological beings, each with its own kind of "depth" - whether these latter be material causes hidden inside our bodily organs or the personal histories that might motivate observable behaviors and processes. We offer these reflections as routes to a better understanding of changes that have occurred and are occurring on the planes of both culture and individual psychological existence.

Sight is usurping touch. Images are deposing bodies. Virtuality is replacing reality. Much of this can be traced back to the advent of the society of the spectacle with its corresponding ocularcentrism, whose tenets were subsequently reinforced by the society of virtual relationships. And now the fear of being contaminated by the COVID virus has further reinforced the tendencies toward decorporealization, dematerialization, and social isolation, at least in terms of body-to-body relationships.

Technologies - including architecture, media, and medicine - have the capacity to redesign our bodies or, at least, our lived bodies. They shape new ways of living our 
corporeal selves, along with new kinds of spaces and new ways of spending our time, and thereby of forging the selves and the relationships that make us who we are [18]. We need to be aware, then, that technologies may not remain extrinsic and neutral devices but indeed are better seen, in many cases, as prostheses that tend to be experientially incorporated as parts of our body and modes of interaction. All this should serve as a warning, as an antidote to the enthusiasm with which we are so often encouraged to embrace the magnificent progress of technology.

To conclude, it is obvious that public health policy in times of pandemic needs to be grounded on a scientific rationale rather than on fears - rational or otherwise - of contamination. An encouragement of irrational fears of contamination can nevertheless be one of its consequences. It is obvious as well that the assessment of the epidemiological efficacy of biopolitical strategies for combating a virus, on one hand, and the question of how human existence is being changed, on the other, are separate issues; and also that the COVID pandemic per se is not the main cause of our destiny of disembodiment and dematerialization. This latter trend, we have argued, has its roots in the modes of social and personal existence that during the last century or more have been shaped by architecture, media, and medicine, as well as by other technologies. The biopolitics of the COVID pandemic does, however, seem to have accelerated these historical trends. As such, its impact can help make us more aware of pre- existing developments in which social distancing was increasingly supplanting social proximity and in which virtual networks substitute for flesh-and-blood encounters. In this sense, the COVID pandemic offers us an opportunity to register the centrality of presence in human existence, to appreciate the importance of the impact that things and other human beings can have on our bodies and our senses - and in general on ourselves as embodied agents.

Obviously, we need to take advantage of the biomedical and biopolitical possibilities that our era's technology provides for us, such as, for instance, how empirical studies can clarify the efficacy of different strategies of social distancing, or the many valuable ways in which virtual reality facilitates online preventive strategies necessary to avoid the actual spreading of a real contagion. This should not, however, prevent us from acknowledging the way these techniques change the perception, representation, and use of our body and of human relationships.

\section{Conflict of Interest Statement}

No conflict of interests

\section{Author Contributions}

The initial conception and first draft was provided by G.S. Subsequent rewriting of the text was done by L.S. and G.S.

\section{References}

1 Gumbrecht HU. Production of presence. What meaning cannot convey. Palo Alto, CA: Stanford University Press; 2004.

2 Straus E. On obsession. Nervous and mental disease monograph, n. 73. New York; 1948.

3 Gebsattel V. Die Welt des Zwangskranken. Mschr Psychiat Neurol. 1938;99:10-74.

4 Binswanger $\mathrm{L}$. Being in the world. Selected papers of Ludwig Binswanger. New York: Basic Books; 1928/1963.

5 Calvi L. Il tempo dell'altro significato. Milano: Mimesis; 2005.

6 Benjamin W, Lacis AN. Walter Benjamin. In: Demetz P. editor, Reflections: essays, aphorisms, autobiographical writings. New York/ London: Harcourt Brace Jovanovich; 1924/1978. p. 163-73. Translated by Jephcott E.
7 Simmel G. In: Landmann M, Susman M, editors. Brücke und Tür. Stuttgart: Koehler; 1957.

8 Benjamin W. The work of art in the age of mechanical reproduction. In: Arendt H, editor. Illuminations. New York: Schocken Books; 1935/1969. Translated by Zoh H (from essay first published in 1935).

9 Jay M. Downcast eyes: the denigration of vision in twentieth-century French thought. Berkeley, CA: University of California Press; 1993.

10 Debord G. The society of the spectacle. New York: Zone Books; 1994/1967. Translated by Nicholson-Smith D. Access 2011 Aug 20. Online at Cddc.vt.edu.

11 Pasolini PP. Il vuoto del potere in Italia. In: Scritti Corsari. Milano: Garzanti; 1975.

12 Deleuze G. Foucault. Minneapolis, MN: University of Minnesota Press; 1988. Translated by Hand $\mathrm{S}$, foreword by Bové PA.
13 Foucault M. The birth of the clinic: an archaeology of medical perception. London: Routledge; 2003.

14 Reinertsen E, Clifford GD. A review of physiological and behavioral monitoring with digital sensors for neuropsychiatric illnesses. Physiol Meas. 2018 May 15;39(5):05TR01.

15 Insel TR. Digital phenotyping: a global tool for psychiatry. World Psychiatry. 2018 Oct; $17(3): 276-7$

16 Stanghellini G, Leoni F. Digital phenotyping: ethical Issues, opportunities, and threats. Front Psychiatry. 2020;11:473.

17 Hacking I. The social construction of what. Cambridge, MA: Harvard University Press; 1999.

18 Hacking I. Historical ontology. Cambridge, MA: Harvard University Press; 2004. 